This is a post-peer-review, pre-copy edited version of an article published in Families, Relationships and Societies. The definitive publisher-authenticated version is available via http://www.ingentaconnect.com/contentone/tpp/frs/2015/00000004/00000002/art00007

\title{
I'm bringing back a dead art': Continuity and Change in the Lives of Young Fathers
}

\section{Fiona Shirani}

\begin{abstract}
Debates about continuity and change in fathering often involve discussion of financial providing and caring involvement. Whilst there remains a lack of consensus about the extent to which these issues are actually new, they are widely recognised as important aspects of cultural constructions of good fatherhood. One group of men who face particular challenges in being seen as good fathers are young dads, who have different resources to negotiate the demands of earning and caring. This analysis elucidates understandings of continuity and change in the lives of young fathers by exploring how they relate to conceptions of involvement and breadwinning. By drawing on two case examples from a qualitative longitudinal dataset, young fathers' relationships to earning and caring over time are explored. This methodological approach serves to illustrate the dynamic nature of young fathers' lives, capturing changes and continuities in their accounts through time.
\end{abstract}

\section{Introduction}

In debates concerning continuity and change in fathering, ideals of 'new' or involved fatherhood are often invoked and in some instances positioned as antithetical to discourses of financial provision and breadwinning. Whilst there is some debate about the extent to which the ideal of the 'new father' is actually new (La Rossa, 1997), involvement with children is now widely recognised by men as an important aspect of contemporary fatherhood (Henwood and Procter, 2003; Morman and Floyd, 2006) and is generally accepted as beneficial for both father and child (Pleck, 1997). However, as women continue to undertake the majority of primary care, debates endure about the extent to which changes are more evident at the level of culture than conduct (Walker and McGraw, 2000:567). The potential discrepancy between the notion of 'being there' and this restricted time commitment has been drawn upon by others, most notably Dermott (2008), to foreground notions of intimate rather than involved fatherhood. Despite a common conception that men are less intimate than women (see Jamieson, 1998, for detailed discussion), there has been a more recent shift towards positioning fathers as active, intimate and emotionally engaged (Miller, 
2010). Dermott (2008) suggests that invoking intimacy as a framework resolves the apparent gulf between culture and conduct. Such 'disclosing intimacy' is not voluntary and equal in the context of the parent-child relationship (Jamieson, 1998) but places importance on fathers 'being there' for and 'really knowing' their child. Snyder (2007) suggests that intimacy underlies notions of quality time rather than quantity time, thus is not about sharing equally in childcare with mothers (see also Featherstone, 2010).

Alongside discussions about increased involvement, understandings of fathers as financial providers continue to resonate, with a 'work focused' model of fatherhood showing continuity over time and across generations (Brannen and Nilsen, 2006). Whilst the reality of dual earner families means that financial provision is not the sole preserve of men (Dermott, 2008), providing for children arguably remains a powerful ideal (Miller, 2010) and appears relevant in structuring conceptions of good fatherhood in men's own accounts (Shirani et al., 2012a).

One group of fathers who are seen as of greater likelihood to experience particular challenges in relation to earning and caring are teenage or young fathers. Young fathers have been relatively neglected in research on teenage parenthood, perhaps due to the assumed conflation between young motherhood and single mothers (Duncan et al., 2010), although the qualitative longitudinal 'Following Young Fathers' study is a notable exception (Neale and Lau Clayton, 2014). Despite decreases in teenage parenthood - now at its lowest level since the 1960s (Office for National Statistics, 2013) - young parenthood continues to be depicted as both a personal and social hazard (Edwards et al., 2010). It may be that the trend towards delayed parenthood positions young parenthood as particularly distinctive, thus parental age at first birth can be regarded as a marker of social polarisation (Thomson et al., 2011).

In contrast to the overriding negative associations with teenage parenthood, some research has identified positive elements. For example through interviews with young fathers, Reeves (2006) found the men describing parenthood as making them more responsible, in contrast to their previous reckless and often criminal behaviour. In these situations, partner or child were positioned as rescuers, thus the pregnancy could be experienced as a positive 'turning point' (Duncan et al., 2010). Some young parents may also see pregnancy as a route out of their own hardship and unhappiness, allowing them to gain independence from their birth family by creating a loving family of their own (Walter, 1986) and providing a sense of capability and satisfaction they were unable to gain through paid employment due to poor qualifications (Cater and Coleman, 2006). Themes of high levels of involvement in childcare 
alongside paid employment have also emerged in research with young men who are not yet fathers in talking about their imagined futures (Edley and Wetherell, 1999).

This paper explores some of these issues in the context of young fathers' lives, initially through an overview of important themes and then through in-depth insights generated as part of two qualitative longitudinal case biographies.

\section{Methods}

Data from this paper come from a sub-sample of eight young men who participated in the Men as Fathers project (MaF) or my linked PhD (Shirani, 2011), which were conducted under the UK wide qualitative longitudinal network 'Timescapes'. MaF sought to explore the experiences of fatherhood through qualitative longitudinal (QLL) interviews with men aged 15-41 across their transition to first-time parenthood and beyond. These men were interviewed once during their partner's pregnancy and twice within the first year afterwards. Whilst working as a researcher on the MaF project (led by Professor Karen Henwood) I undertook a PhD on the 'right time' for fatherhood, which involved one-off qualitative interviews with a sample of men who made an early or late transition to fatherhood. Interviews were semi-structured and some incorporated the use of visual methods.

Most of the studies of fatherhood represent one off 'snapshots' (Neale and Flowerdew, 2003) from single interviews or survey questionnaires, giving little indication as to how men may think differently about fatherhood at other time points in their life. Postmodern sociological perspectives in particular highlight a dynamic world in constant change, the nature of which can be difficult to elucidate with a snapshot approach. In contrast, a QLL study provides the opportunity to consider fluctuations and changes across the life course and the repercussions of these. The benefits of qualitative research in general, such as rich understanding of subjective experiences, are expanded by QLL, whilst the accumulation of data in QLL provides a better understanding of the individual, although not necessarily the 'truth of that person (Thomson and Holland, 2003), offering a more substantial base for writing about identity than a one-off approach (McLeod, 2003). Following people over time also provides an opportunity to explore how and why they make individual choices that then add up to particular cumulative trajectories (Corden and Millar, 2007).

QLL data represents multiple possibilities for analysis. For example, it requires working in two temporal dimensions: diachronically, through time, and synchronically cross-cutting at one point in time, as well as the articulation of the two (Elliott et al., 2008). Data were initially 
analysed thematically across each wave of interviews, which enabled emerging themes to inform future rounds of data collection. Both studies were designed to elicit data in relation to specific aspects of fatherhood discussed in the research literature (such as providing, ideas of the 'new' father), whilst also allowing opportunity for the participant to raise other issues. When further waves had been completed, data could also be analysed over time to form a type of 'case history' about each participant (Thomson, 2007), foregrounding change over time. Here I present data that emerged in relation to two main themes before moving on to in-depth qualitative longitudinal case studies of two young men.

In this paper, I foreground the experience of those across the two studies who made an early transition to fatherhood. These young men were aged between 15 and 22 at the time of the child's birth. Five were cohabiting with their partners (in some cases in the homes of their own parents) and three were living separately from the child's mother. Three were employed in manual occupations or apprenticeships; four were students or in training programmes and one was unemployed. The men were all White British, with the exception of one young father from a South European country. They were recruited through a variety of avenues, including via social workers, community organisations, advertisements and personal contacts.

\section{Data}

When asked to reflect upon the timing of pregnancy, all the young men described their partners' pregnancies as unplanned and recounted their experience of finding out in terms of shock or surprise. Consequently, young men often saw fatherhood as a disruption to their imagined futures (Shirani and Henwood, 2011a), as they had not anticipated becoming fathers for several years, if at all. The first section of data analysis explores some of the challenges they faced negotiating this early transition to fatherhood in relation to working and caring, which emerged as major themes in the initial analysis. All names used are pseudonyms.

\section{Earning}

One of the most pressing concerns the young men described was their employment and economic circumstances. The importance of financial provision was highlighted across all the young men's accounts, yet their responses to dealing with financial responsibility varied. For some this meant giving up or postponing their attempts to gain further qualifications in order to generate money through working in low-skilled jobs. 
I started working at [factory], it was probably the worst job l've ever had in my life. And then you get the feeling sinks in you know of I could be doing this for the rest of my life because l've gotta provide for this child until the child's at least 16/17/18 you know what I mean? (Owen, 18, single, in work-based training)

For young men like Owen, this raised concerns about being trapped in low-status employment for the foreseeable future.

Despite associations being drawn between social class and fathering a child at a young age (Dearden et al., 1994), two men from middle-class backgrounds participated in my PhD research. These men opted for a different approach to work; continuing their higher education in the belief that gaining qualifications would enable them to have higher earning jobs in the long-term, which would be better for their family. The main difficulties relating to parenthood that these young fathers articulated were constrained choices in the initial stages of fatherhood; not being able to provide their child with the best start as they were forced by restricted financial circumstances to live in areas with low cost housing and high crime rates:

we live here 'cause it's good for university ... essentially there's no choice in terms of neighbourhood and stuff. I never wanted to bring up a kid in the inner city, that's essentially what l'm doing now for the first few years ... I want to move, essentially I don't want to live here as quick as possible because essentially it's a shithole (amusement) ... I don't want him to grow up in that environment. (Johnny, 22, living with partner and child, student)

For these two young men, the transition to fatherhood did not prevent them following their chosen career paths; indeed it highlighted the importance of having a stable career in the future.

For those young fathers not in work, education or training, the baby provided an impetus for gaining qualifications or finding employment in order to provide financially and be a positive role model, thus prompting a positive transformation in their life trajectories. In this way, conception could provide an opportunity to strengthen or embark upon a more conventional path (Augustine et al., 2009).

Parental support was important for the majority of young fathers and the young men often spoke about their fathering in comparison with their own experience of being parented (see Baker and Bosoni, this issue). Some of the young dads received extensive financial support from parents and were still living at home. Therefore, for these young men, some of the difficulties of parenthood were buffered by their own parents, who stepped in to provide 
some aspects of parental roles for the new baby (i.e. provision of money and suitable housing). Whilst the young men expressed gratitude for this support, this dependence was challenging as the men sought to emphasise their own status as fathers and their parents as supporting them in this in their role as grandparents.

\begin{abstract}
Having to depend on your parents for living in their place and all the other things that go with it ... I think it's extra hard when like I say you're living in someone else's house, you're always constantly worried about money and trying to save where you can like. So yeah I would say it's probably slightly difficult, like I say more stressful ... especially with Tara as a young mother as well "cause she was really dependent on her mother at first. You are made to feel - well I was anyway - I can understand how you feel well what's the point in me being here? I might as well go (laughs) if you know what I mean. (Ryan, 19, living with partner and child, apprentice builder)
\end{abstract}

Becoming a parent was one way in which young people could access forms of responsibility and recognition associated with adulthood, yet in doing so they generally confirmed their economic dependence on their own parents (Thomson, 2009; see also Neale and Lau Clayton, 2014). As Ryan indicates, whilst valuing the support provided by his parents, this compounded his own sense of helplessness, and, he felt, contributed to initial difficulties in establishing a father role.

\title{
Caring
}

All study participants were committed to a model of involved fatherhood and articulated the importance of 'being there'. How this transpired in terms of parenting practice varied widely, depending on the participants' living situations and the extent of childcare they were willing or practically able to undertake. Whilst notions of fairness in terms of childcare responsibility were important to some (see Ives, this issue), other young men acknowledged that the mother of their child did the majority of the difficult or demanding tasks. In terms of the relationship with the child, their conception of involvement more closely resembled a model of disclosing intimacy (as discussed above) than one based on quantity time together. However, regardless of the extent of their involvement, these young men were able to distinguish themselves from other teenage fathers who refused to acknowledge any responsibility for their children:

I decided that I weren't gonna be hypocritical because I'm the first person in the world to turn round and go "I can't believe him, he's not about for the baby" and straight away I said right this is time to prove that you're not a hypocritical type of person. Straight away I said I'm gonna be here for my daughter. (Owen) 
Although Owen was not in a relationship with the child's mother at any point, he described his commitment to being an involved father and has cared for his daughter alone two days a week from birth. In committing to involved caring, young fathers were opting for a lifestyle that was significantly different to that of their peers. Whilst initially babies were treated as something of a novelty by friends, not being able to partake in the same social activities as they had dome before the baby arrived, given their newfound caring responsibilities, meant some men found it difficult to keep up with their friendship groups, which could lead to a sense of isolation.

Before Liam was born like I say you've got your friends who you go drinking with, l've lost contact with all them. Which you do regret but they're still going out doing their thing and there's only a certain amount of times they'll text you to go out before they stop texting like. (Ryan)

This sense of isolation was sometimes compounded by concerns about 'missing out' on an individualistic life course phase, where they could focus on their own interests without having responsibility for dependent others, as they saw many of their peers being able to do. However, the young men frequently suggested this phase could be returned to in the future when children left home, as they would still be relatively young, therefore they would not miss out on these experiences in the context of their overall life course.

Making the transition to parenthood at a different time to their peers did prompt a sense of isolation, but being out of time was not experienced as wholly problematic. For example, it was suggested that being somewhat outside the norm made it easier for the young men to behave as they wanted, as they were less concerned about other people's reactions, or feelings of competitiveness with other parents, than they perceived fathers of older ages to be (see e.g. Shirani et al., 2012b for discussion). Subsequently they felt it was easier for them to behave in emotional or playful and silly ways with the child.

I s'pose 'cause we're the first ones doing it, besides parental stuff that we read it's essentially, I dunno, we're almost doing it how we like and not a hundred and one different inputs. There's still a lot of sort of inputs into us, but you know, I s'pose also being younger l've got no inhibitions about acting like a prat around him, I dunno maybe l'd have been a bit more serious if I was a few years older. I'll quite happily walk around Sainsbury's just pulling faces and making noises at him or whatever. (Johnny)

Several of the men felt that others had reacted negatively to their young fatherhood because of perceptions they were not in a position to take on the responsibilities of parenthood. Some 
sought to justify their experience through reference to changes in the average age of childbearing over time, arguing that in previous generations becoming a father at their age would have been the usual practice. These efforts to illustrate continuity with previous generations can be seen as an attempt to position young fatherhood as ordinary rather than problematic.
People turn round to me and go "oh you're young for a dad" but I remember people, you think about thirty/forty years ago the average age of people to have kids was eighteen you know what I mean; women come straight out of school, marry straight away and have kids straight away. I think I'm, I think I'm bringing back a dead art (amusement) bringing back an old-fashioned sense (Owen)

By situating his fatherhood status as legitimate in a wider historical context, alongside his commitment to an involved carer identity, as outlined above, Owen makes efforts to position himself as a good father, in contrast to contemporary societal expectations of teenage parents.

In light of this brief exploration of major themes raised by the young men, the following section focuses on the longitudinal cases of two fathers to illustrate how these issues emerged and receded over time in their accounts of the first year of fatherhood.

\section{Aaron}

Aaron was 14 years old when his on/off girlfriend Kelly (aged 15) became pregnant. At the time of the first interview he was living with his father and was not in education or employment, having been expelled from school. On initially finding out about the pregnancy, Aaron had wanted Kelly to have an abortion, feeling that he was too young for fatherhood.

I was 14, still in school and I dunno I just didn't think I was ready for a baby ... just too young and too much life ahead of me, didn't want to have kids yet until I was older, tie me down and things like that ... just thought maybe l'd have kids when I'm older and I have a house and I'm settled down, thought I may have children when I'm older but it happened sooner than I thought like.

However, when it became clear that Kelly wanted to continue with the pregnancy, Aaron described how he intended to be an involved father, making recourse to popular ideas about 'being there'. Yet despite this commitment, for Aaron becoming a father at a young age was a source of anxiety as he felt unable to provide all the things he felt a good dad should be able to; particularly money. 
I've always know l'd be there for the baby and I'm going to be a father to the baby. But um just scared as well, scared, worried ... I ain't got no money and I thought how am I supposed to be a dad and do what dads do if I ain't got no money to spend on anything? I'm not going to be able to buy her anything

By the second interview when his daughter Mia was a few months old, Aaron and Kelly had separated. This led to Aaron seeing Mia less frequently (around three times a week for short periods) as he was dependent on Kelly to facilitate his visits, and during arguments she had reportedly threatened to refuse contact altogether. Aaron attributed the separation to Kelly's parents, who he felt had disapproved of him as a bad influence, which had strained the couple relationship. Whilst Aaron wanted to see his daughter more frequently, he was confident that time with her would increase in the future when she was less dependent on her mother (Shirani and Henwood 2011b). In the meantime, he focussed on gaining qualifications in order to secure future employment.

I'm a father but I'm not exactly a parent if you know what I mean; she doesn't live with me. I'm just doing the best that I can to see her at the moment, get GCSEs and see what happens in a couple of years' time when I can try and have her myself

After Mia's birth, Aaron completed his alternative education course and had subsequently enrolled at a local college where he was taking his GCSEs. Whilst in education, Aaron's financial circumstances were constrained as he was too young to be eligible for many of the part-time jobs that may otherwise have been available to him. However, he did not express particular concern about this as his own father was able to help out with the baby financially.

Well my dad gives her money as well because I haven't, I'm not working I'm still in college. My dad's been giving her money as well and if ever she needs anything like nappies or I dunno milk or whatever l'll go out and buy whatever she needs ... I help out with things ... obviously he's not the dad and he's just helping me out and just wants to see her. He loves Mia and loves seeing her; he understands that l'm the dad

By this interview some of Aaron's worries had been alleviated as his own father was facilitating financial support for the baby. Unlike some young parents who resented this increased dependency on their own families, as discussed above, Aaron appeared comfortable with these financial arrangements. However, his emphasis that this does not change his fatherhood status suggests he recognises the extent to which his own father is taking on the responsibilities of parenthood. 
By the third interview when Mia was 14 months old the relationship between Aaron and Kelly had deteriorated further and he had not seen Mia for two weeks. This was problematic for his narrative of good fatherhood, which changed from an emphasis on 'being there' to 'trying my best'. It was the effort to see her that he felt distinguished him from other fathers who did not see their children.

Maybe I'm not what l've stated as a good father but I'm trying my best really. I mean I'm just trying to see her as much as I can and spend as much time with her as I can.

Although his relationship with Mia had differed from his initial ideals, becoming a father had proved to have an important influence on Aaron's life. Notably, he had re-engaged in education with the long-term motivation of finding a job so he could financially support his daughter.

Definitely, that's what's done it really when Mia was born, you know things changed, I looked at things differently ... I just decided I wanted to do something, go back to school and get GCSEs 'cause I don't wanna be growing up and, you know if I didn't go back to school then I wouldn't be doing anything now, I wouldn't be doing anything in September and I wouldn't have any GCSEs so I wouldn't have been able to get into college, so l'd have ended up stuck in a lazy job on the minimum wage

By exploring Aaron's experiences over time, the challenges he experienced in living up to the ideals of good fatherhood he initially held are highlighted. Whilst his narrative changes from 'being there' to 'doing my best', it is the continuing commitment to making an effort in relation to Mia that he sees marking him out as a father. Although fathering was not straightforward for Aaron, the transition to parenthood did have a positive impact on other areas of his life; a return to education, change in friendship groups to avoid getting into trouble, and an improved relationship with his own father.

\section{$\underline{\text { Scott }}$}

Scott was 22 years old at the time of the first interview, when his partner was eight months pregnant. He was unemployed following a period of training to achieve I.T. qualifications and was volunteering with a local community organisation. Scott was not living with his partner 
Carys (who was several years older and was living with her two children from previous relationships) but intended to move in with her around the time of his child's birth.

When asked what being a good father involved, Scott articulated a similar response to Aaron; highlighting financial provision, being a role model and 'being there'.

Role model, first thing off the top of my head; role model. And um provider ... I s'pose it would involve bringing someone up from birth, being there for them, making sure that they understand what's right and what's wrong.

Whilst he described a positive relationship with his partner's children, he was clear that he did not see himself in a stepfather role towards them and therefore that the birth of his own child would represent a new father identity. Like Aaron, Scott felt that imminent fatherhood had brought about significant changes for him, including a commitment to providing financially.

I was abysmal, undesirably wrecked, I had no kind of direction or anything. But since we found out that Carys was pregnant l've just tried to do anything possibly to try and gain any qualifications, find any kind of work, l've been doing any kind of work I possibly can as well, which is hard to find mostly, more than anything.

The couple did move in together for a short period when their son was born. However, by interview two, when Alfie was nearly four months old, the couple had separated and Scott was unable to see his son. He described the breakdown of their relationship as sudden and acrimonious, which had led to contact difficulties.

But um no it's turned really really nasty, really nasty. To the point of I was going there on the basis of seeing my son and seeing him, checking up that he was okay. We had a mutual agreement of on the Saturdays I could have Alfie til the Sunday night um and that went from over the weekends to just a Saturday, and then it went from just a Saturday to a few hours on a Saturday, to an hour on a Saturday, to um, it's turned round now to I can't see my son unless it's in her house.

Scott had sought legal advice and was due to begin mediation sessions with Carys a few days after the interview. In the meantime, he reported that his solicitor had advised him not to give Carys any money for Alfie, but to set up a bank account for him and make regular deposits to demonstrate a commitment to providing financially for his son as an aspect of responsible fatherhood. 
Since being asked to leave Carys's house, Scott described himself as having 'no fixed abode', spending some time staying with his parents (around one hour away), staying with friends or 'sleeping rough'. He was committed to maintaining a relationship with Alfie, although recognised that he was not in a position to request full custody, given his unstable living situation and unemployment.

I just want my visitation rights, my parental responsibility basically. My name's on the birth certificate and he's also my son but he's not being treated like he's my son ... I'm a lot more than a sperm donor. I was there during the pregnancy, during the birth, and up until the relationship really broke down and after. But no it's a matter of I said l'd always be there for my son and that's what I aim to do. And I'll move heaven and Earth to try and do it

Between interviews Scott had had some temporary work but felt that the economic downturn had made the job market much more competitive, which created difficulties for him in finding suitable employment. Scott was hopeful of being part of a social enterprise with the community organisation he volunteered for, which he thought would enable him to use the skills he had gained and provide a regular income.

The final interview took place on Alfie's first birthday by which time Scott was 23. He had been able to move into a flat with a friend, which offered some stability, although this was not considered suitable accommodation for his son and took him further away from the area where Alfie lived:

I've gotta go even further to see my son and um at the moment, current time, it's taking from eight o'clock in the morning on a Saturday morning till five to ten for me to get to [area], catching two buses ... I don't mind doing it at all because I know at the end of it is Alfie

Again, between interviews Scott had had a series of temporary jobs, none of which had 'worked out' so was still unemployed. The financial crisis had had an impact on the sources of funding which would have made the social enterprise possible, and a key member of the community group who had supported Scott left to work elsewhere. Subsequently his involvement in the group waned, meaning he lost what had been a key source of support and stability.

Following legal proceedings Scott was able to see his son via supervised visits at a contact centre for 90 minutes a week. At the time of the third interview, Scott was waiting for a court hearing to establish his visitation rights. 
No it's um, oh finances argh, credit crunch and everything. It has been tough, it's been really tough, it's been really tight as well. There's been occasions where I've had to sell a few things to make sure l've got the bus fare to go and see Alfie ... But money-wise oh disaster! Being there for Alfie, I don't think I'm doing too bad. I've been told, you know a lot of people are surprised that a guy my age is actually stepping up to the plate 'cause there are a lot of people my age I know of myself just don't wanna bother, don't wanna know, quite happy to plod on in their own little world without bothering with their kids. I think it's disgusting

Through positioning himself in contrast to fathers who make no effort to see their children Scott illustrates a position that, although diverges from his own ideal of fatherhood, indicates a commitment to his child which in itself is seen as a fundamental aspect of good fatherhood.

By exploring the experiences of these men over time through a qualitative longitudinal study, a more detailed account of the dynamic nature of young fatherhood and the particular challenges these men face emerges than would be possible in a one-off snapshot approach (Neale and Flowerdew, 2003). For both Aaron and Scott, their initial ideals of good fatherhood were not realised, however they see their continuing commitment to parenting as marking them out as good fathers, which is highlighted by the comparisons they draw with men who take no responsibility for their children.

\section{Conclusions}

This paper has sought to elucidate issues of continuity and change in fathering as they arise in the lives of young men, and these issues have been made visible in three main ways. Firstly, fathers alluded to the continuing relevance of financial provision for their understanding of good fatherhood, even when they were not able to contribute to the extent they would have liked. However, these young men were also clear that fathering involved much more than providing materially for their child and sought some emotional involvement, to varying degrees. In particular, for co-resident fathers, commitment to fatherhood and involvement in caring represented a significant rupture to their previous lifestyles and often resulted in a change of friendship groups. Ideals of 'being there' were important in the young men's narratives of good fatherhood, although the reality of their circumstances meant for some this changed to 'doing my best' as an alternative indicator of good fatherhood. This shows that contemporary parenting ideals of involvement appeared to exert a powerful 
influence on the young men's conceptualisations of good fatherhood, which they made efforts to realise even in difficult circumstances.

Secondly, by focusing on two longitudinal case biographies, the analysis has illustrated changes and continuities in men's accounts over time. As a consequence of their circumstances these two young men spent the least amount of time with their children of any men in the sample. Subsequently, it might be suggested that fatherhood had little impact on their lives, yet looking in detail via a case biography approach shows that this is not the case. For Aaron, becoming a father prompted him to re-engage with education, with the long-term aim of gaining employment to support his child. Whilst initially hopes of involvement with his child were high, by the third interview contact had stopped altogether (albeit he felt temporarily) but he continued to anticipate greater involvement in the future (Shirani and Henwood, 2011b). Arguably for Aaron, the changes in his day-to-day life after becoming a father were small, as the child's mother retained primary responsibility for care. However, his account indicates the kind of extensive changes fatherhood had brought to his future trajectory, which was an experience shared by many of the young dads. Whilst Scott was also unable to provide financially or care for his son in the way he had initially anticipated, he felt that his actions across the first year demonstrated his commitment to being an engaged father, in itself an indication of good fatherhood. Following the experience of a sudden relationship breakdown and insecure job situation during the economic downturn, Scott was reluctant to discuss his longer-term future (Shirani and Henwood, 2011a), although, like Aaron, felt his level of involvement would increase over time. This was partly due to a sense that their involvement as fathers would be easier with an older child, who could engage in and appreciate specific activities. Presenting data in this way demonstrates the benefits of QLL research in illustrating the practical barriers to achieving initial fatherhoodideals over time, which would not have been visible in a one-off interview approach. Research taking an even longer perspective could help to expand these insights further.

Finally, some of the young men described their perceptions that others viewed them negatively for having a child early in life (although they indicated that most disapproval was directed towards the child's mother). Although perceptions of teenage parenthood are overwhelmingly negative, exploring the accounts of these young men shows how becoming a parent had a positive impact on some aspects of their lives, for example, by encouraging them to re-engage with education and employment, or stop friendships with those they considered to be a bad influence. Although some of the young men struggled to realise their ideals of good fatherhood, greater recognition of the efforts they are making could help them 
to avoid feeling demoralised. Despite continuing concern about teenage parenting, rates appear to be decreasing, which may be one of the reasons that most of these young men did not know other fathers in the same position. Instead some made reference to previous generations as legitimation for their own timing of fatherhood. This sense of isolation could be particularly challenging for the men, who often struggled with knowing how to be a father. In the circumstances where others in a similar position were available to talk this was greatly valued and could help to support young fathers' engagement with their children. Subsequently, practitioners working with young men could potentially make an important contribution by connecting teenage fathers with one another in order for them to share their experiences.

Bringing together these different perspectives on continuity and changes further elucidates current issues and challenges in the lives of young fathers, whilst a qualitative longitudinal approach provides insight into changes over time, highlighting the dynamic and nuanced nature of their fathering experience.

\section{Acknowledgements}

I would like to acknowledge Professor Karen Henwood, Principal Investigator of the Men as Fathers project. I am also grateful to the reviewers for their helpful comments. Some of the data presented in this paper are drawn from projects supported by ESRC grants numbers R02225016 and RES-347-25-0003.

\section{References}

Augustine, J.M. Nelson, T. and Edin, K. 2009, Why Do Poor Men Have Children? Fertility Intentions among Low-Income Unmarried U.S Fathers. In Doucet, A. Edwards, R. and Furstenberg, F.F. (Eds) The Annals of the American Academy of Political and Social Science. Special Issue on Fathering across Diversity and Adversity: International Perspectives and Policy Interventions. 624, 1, 91-117.

Brannen, J, and Nilsen, A, 2006, From Fatherhood to Fathering: Transmission and change among British fathers in four-generation families. Sociology, 40, 2, 335-352. 
Cater, S, and Coleman, L, 2006, Planned Teen Pregnancy: Perspectives of young parents from disadvantaged backgrounds. Bristol: Policy Press.

Corden, A. and Millar, J. 2007, Qualitative Longitudinal Research for Social Policy Introduction to Themed Section. Social Policy and Society. 6, 4, 529-532.

Dearden, K, Hale, C, and Blankson, M, 1994, Family Structure, Function, and the Early Transition to Fatherhood in Great Britain: Identifying Antecedents Using Longitudinal Data. Journal of Marriage and Family, 56, 4, 844-852.

Dermott, E, 2008, Intimate Fatherhood: A Sociological Analysis, London: Routledge.

Duncan, S, Alexander, C, and Edwards, R, 2010, What's the problem with teenage parents? in S. Duncan, R. Edwards, and C. Alexander, (eds) Teenage Parenthood: What's the Problem? London: The Tufnell Press.

Edley, N. and Wetherell, M. 1999, Imagined futures: Young men's talk about fatherhood and domestic life. British Journal of Social Psychology. 38, 2, 181-194.

Edwards, R, Duncan. S, and Alexander, C, 2010, Conclusion: Hazard warning, in S. Duncan, R. Edwards, and C. Alexander, (eds) Teenage Parenthood: What's the Problem? London: The Tufnell Press.

Elliott, J. Holland, J. and Thomson, R. 2008, Longitudinal and Panel Studies. In Alasuutari, P. Bickman, L. and Brannen, J. (eds) Handbook of Social Research Methods. London: Sage. pp228-248.

Featherstone, B, 2010, Writing fathers in but mothers out!!! Critical Social Policy, 30, 2, 208224.

Henwood, K, and Procter, J, 2003, The 'good father': Reading men's accounts of paternal involvement during the transition to first-time fatherhood. British Journal of Social Psychology, 42, 3,337-355.

Jamieson, L, 1998, Intimacy: Personal relationships in modern societies, Cambridge: Polity Press. 
La Rossa, R, 1997, The Modernization of Fatherhood: A Social and Political History, London: University of Chicago Press.

McLeod, J. 2003, Why we interview now - reflexivity and perspective in a longitudinal study. International Journal of Social Research Methodology. 6, 3, 201-211.

Miller, T, 2010, Making Sense of Fatherhood: Gender, Caring and Work, Cambridge: Cambridge University Press.

Morman, M, and Floyd, K, 2006, Good Fathering: father and son perceptions of what it means to be a good father, Fathering, 4, 2, 113-136.

Neale, B, and Flowerdew, J, 2003, Time, texture and childhood: the contours of longitudinal qualitative research. International Journal of Social Research Methodology, 6, 3, 189-199.

Neale, B. and Lau Clayton, C. 2014, Young Parenthood and Cross-Generational Relationships: The Perspectives of Young Fathers. In Holland, J. and Edwards, R. (eds) Understanding Families Over Time: Research and Policy. Basingstoke: Palgrave Macmillan.

Office for National Statistics, 2013, Teenage pregnancies at lowest level since records began. Part of Conception Statistics, England and Wales, 2011 release. Available at: http://www.ons.gov.uk/ons/rel/vsob1/conception-statistics--england-and-wales/2011/styconception-estimates-2011.html

Pleck, J, 1997, Paternal Involvement: Levels, Sources and Consequences. In M. Lamb (ed) The Role of the Father in Child Development ( $3^{\text {rd }}$ Edition), New York: Wiley and Sons.

Reeves, J, 2006, Recklessness, Rescue and Responsibility: Young Men Tell Their Stories of the Transition to Fatherhood, Practice, 18, 2, 79-90.

Shirani, F, 2011, The Right Time for Fatherhood? A Temporal Study of Men's Transition to Parenthood, Cardiff University, unpublished PhD thesis.

Shirani, F, and Henwood, K, 2011a Taking One Day at a Time: Temporal experiences in the context of unexpected life course transitions, Time and Society, 20, 1, 49-68. 
Shirani, F, and Henwood, K, 2011b Continuity and change in a qualitative longitudinal study of fatherhood: Relevance without responsibility, International Journal of Social Research Methodology, 14, 1, 17-29

Shirani, F, Henwood, K, and Coltart, C, 2012a 'Why aren't you at work?': Negotiating economic models of fathering identity, Fathering, 10, 3, 274-290.

Shirani, F. Henwood, K. and Coltart, C. (2012) Meeting the challenges of intensive parenting culture: gender, risk management and the moral parent. Sociology. 46(1) 25-40.

Snyder, K.A, 2007 A Vocabulary of Motives: Understanding How Parents Define Quality Time, Journal of Marriage and Family, 69, 320-340.

Thomson, R, 2009, Unfolding lives: youth, gender and change, Bristol: Policy Press.

Thomson, R. and Holland, J. 2003, Hindsight, foresight and insight: the challenges of longitudinal qualitative research. International Journal of Social Research Methodology. 6, 3, 233-244.

Thomson, R, Kehily, M.J, Hadfield, L, and Sharpe, S, 2009, Making Modern Mothers, Bristol: Policy Press.

Walker, A, and McGraw, L, 2000, Who is responsible for responsible fathering? Journal of Marriage and Family, 62, 2, 563-569.

Walter, C, 1986 The Timing of Motherhood: Is Later Better? Massachusetts: Lexington Books. 